Original Research Paper

\title{
Copper (I)-Nicotinate Promotes Gene Expression of CYPs that Produce M1 and Q1 in Aflatoxicosed Rats
}

\author{
${ }^{1{ }^{*}}$ Mohammed Salah, ${ }^{1 \#}$ Laila Mostafa, ${ }^{2}$ Tahia H. Saleem, ${ }^{3}$ Ahmed R. Shatat, \\ ${ }^{1}$ Obeid Shanab, ${ }^{4}$ Enas A. Noseer, ${ }^{5}$ Muammar Y. Nassar and ${ }^{2}$ Ahmed Y. Nassar \\ ${ }^{I}$ Department of Biochemistry, Faculty of Veterinary Medicine, South Valley University, Qena, Egypt \\ ${ }^{2}$ Department of Biochemistry, Faculty of Medicine, Assiut University, Assiut, Egypt \\ ${ }^{3}$ Department of Chemistry, Faculty of Science, Al-Azhar University, Assiut, Egypt \\ ${ }^{4}$ Department of Biochemistry, Faculty of Veterinary Medicine, Aswan University, Aswan, Egypt \\ ${ }^{5}$ Department of Biochemistry, Dongola University, Sudan
}

Article history

Received: 07-11-2019

Revised: 06-01-2020

Accepted: 27-01-2020

Corresponding Author: Mohammed Salah

Department of Biochemistry,

Faculty of Veterinary

Medicine, South Valley

University, 83522, Qena, Egypt

Email: salah-Bio@vet.svu.edu.eg

${ }^{\#}$ These authors contributed equally to this work.

\begin{abstract}
Aflatoxin-contaminated food poses a serious risk to both human and animal health. Copper (1)-nicotinate $\left(\mathrm{Cu}^{+}\right.$-nicotinate) complex potentiated the prophylactic effect against chronic aflatoxicosis in the experimental animals through the synthesis of less toxic metabolites M1 and Q1 which are easily excreted in urine. To investigate the action of the safety $\mathrm{Cu}^{+}$-nicotinate complex on gene expression of Cytochrome 450 (CYP450) system, the liver tissue samples of orally administered rats for 3 weeks with aflatoxin B1 (AFB1; $30 \mu \mathrm{g} / \mathrm{kg}$ body weight), with and without association of the copper complex $(400 \mu \mathrm{g} / \mathrm{kg}$ body weight) were assayed for their gene expression of CYP450 families including 1A2, 3A2 and $2 \mathrm{C} 11$ as well as histopathological examination of the hepatic tissue samples was performed. The obtained data denoted that the $\mathrm{Cu}^{+}$-nicotinate complex significantly reduced gene expression of CYP2C11 and CYP3A2 that enhancing the most toxic epoxide metabolite. On the contrary, this complex enhanced the expression of CYP1A2 that synthesize the less toxic metabolite M1 and Q1. The histopathological examination mostly confirmed such observation as the signs of aflatoxicosis were absent in $\mathrm{Cu}^{+}$-nicotinate-treated group. Consequently, it could be predicted that the $\mathrm{Cu}^{+}$-nicotinate complex may be medically used as an inhibitory food additive agent against exposure of aflatoxicosis in the intact animals since the complex contains the copper and nicotinic acid, the two daily required biochemical elements for sustaining live in healthy conditions.
\end{abstract}

Keywords: Aflatoxin B1, Copper-Nicotinate, Cytochrome P450, Metabolites, Food Additive

\section{Introduction}

Aflatoxins are a group of naturally occurring secondary fungal metabolites secreted mainly by Aspergillus flavus and Aspergillus parasitcus (Luttfullah and Hussain, 2011). They are common contaminants of many staple foods especially maize, groundnuts and subsistence farming communities in developing countries located in tropical and sub-tropical regions (Kew, 2013; Mulenga and Siziya, 2019). Moreover, they contaminate milk and eggs of animals and birds which consumed foods contaminated with aflatoxins. Therefore, aflatoxins are a human food safety risk in both plant and animal products (Sarma et al., 2017).
Aflatoxins cause severe health hazards to both animals and humans. The disease caused by aflatoxins known as aflatoxicosis and there are two forms of aflatoxicosis: Acute and chronic form. The acute form is characterized by severe liver damage ended by death and chronic form is manifested by reduced production, feed intake, weight gain as well as immunosuppression in animals, while in humans is manifested by Hepatocellular Carcinoma (HCC) (Balina et al., 2018). Aflatoxin B1 (AFB1) is the most widespread and toxic form of aflatoxins. AFB1 causes severe liver damage and has been embroiled in expanding the incidence of HCC (Rotimi et al., 2019). 
Cytochrome P450 (CYP450) is a hemeprotein system consists of a group of enzymes localized in the hepatocytes that have a role in metabolizing various types of xenobiotics, AFB1 is one of these compounds bioactivated by CYP450 (Diaz et al., 2010). Molecular biological techniques on hepatic microsomes of induced aflatoxicated rats revealed that the AFB1 8, 9-epoxide could be biotransformed from AFB1 by CYP2C11, 3A2 but not by 1A2 (Shimada et al., 1987; Halvorson et al., 1988; Imaoka et al., 1992). The AFB1 8,9-epoxide covalently bound $\left(\mathrm{N}_{7-}\right.$ guanyl) DNA of the target hepatic tissue in the aflatoxicated animal even with low doses of AFB1 range (Wang and Groopman, 1999). The author recognized that $\mathrm{AFB} 1-\mathrm{N}_{7}$ guanine adduct was removed from DNA rapidly to be excreted exclusively in urine of exposed rats inducing HCC that was demonstrated by the studies on p53 suppressive gene where high-frequency p35 mutations $(\mathrm{G} \rightarrow \mathrm{T})$ transversion at codon 249 of hepatic chineses in South African subjects (Wang and Groopman, 1999; Kew, 2013; Lin et al., 2014). The authors provided that CYP450 families $1 \mathrm{~A}, 2 \mathrm{~B}$ and $3 \mathrm{~A}$ metabolizes concomitantly the AFB1 into the less toxic members (Ramsdell et al., 1991; Raney et al., 1992).

Antioxidants exhibit anti-carcinogenic properties by inducing cellular detoxification pathways in exposed experimental animals to AFB1 especially phenolic compounds such as beta hydroxy toluenes (Monroe et al., 1986; Monroe and Eaton, 1987; Mandel et al., 1987; Penning, 2011). Copper $(\mathrm{Cu})$ is considered a crucial trace metal that can readily be transformed between divalent oxidized $(\mathrm{Cu}++)$ and monovalent reduced $(\mathrm{Cu}+)$ states in biological media, making it a favorable cofactor for various enzymes implicated in several biochemical reactions (Grubman and White, 2014). Copper is necessary for the activity of multiple coenzymes indispensable for several physiological functions and biochemical pathways (Linder and Linder, 1991; Vančo et al., 2008). Copper complexes have the ability to modulate copper homeostasis in various tissues to provide a protective impact against multiple disorders (Belicchi Ferrari et al., 2002).

Biologically active copper complexes showed antioxidant therapeutic activity specifically $\mathrm{Cu}^{+}$-nicotinic acid complex (Sorenson, 1987). The antioxidant activity of $\mathrm{cu}^{+}$-nicotinate complex was attributed to its superoxide dismutase-mimicking activity, scavenge free radicals, control nitric oxide level, accelerate the excessive production of antioxidant enzymes such as glutathione peroxidase, glutathione-s-transferase and catalase as well as prevent blood capillary damage with stimulating blood flow (el-Saadani et al., 1993; Suksrichavalit et al., 2008; Shatat et al., 2013; Lupo et al., 2017).

This complex showed a pharmaceutical activity against Newcastle disease (Musa et al., 1987), anti- inflammatory effect against drastic induced rat model for gastric ulcer (el-Saadani et al., 1993), reduction of adverse effects of 5- fluorouracil in HCC persons (El-Saadani, 2004), prophylactic effect against induction of fatty liver in rats (Salama et al., 2007) as well as curative effect against induced rat burn skin injury (Nassar et al., 2012). Previously this $\mathrm{Cu}^{+}$-nicotinic acid complex was tested as a potent antagonist in induced aflatoxicated rats (Shatat et al., 2013). Regarding its prophylactic effect against aflatoxicosis, we have assayed the less toxic metabolites in the excreted urine (Nassar et al., 2014). The prominent detoxification action of the copper complex was attributed to the divergent efficacy of antioxidant cytochrome families especially those enhancing the less toxic metabolites M1 and Q1 (Nassar et al., 2014).

The present study has been designed to clarify the efficacy of $\mathrm{Cu}^{+}$-nicotinic acid complex on gene expression that codes to the less toxic metabolites CYP450 Families M1and Q1. The test that should be confirmed histologically on hepatic tissue sections.

\section{Material and Methods}

\section{AFB1 Preparation}

The provided an isolate aspergillus flavus from the Fungi research institute, Assiut University-Egypt was cultivated by potato dextrose Broth method (Booth, 1971). The biosynthesized AFB1 of the fungal growth was harvested as mentioned previously (El-Kady and Moubasher, 1982). AFB1 was extracted in chloroform where the organic layer was treated with anhydrous NaSo4. On silica gel colon chromatography AFB1 fraction was isolated and purified. The toxin was suspended in maize oil and checked on precoated plates of silica gel. The chromatographic zones were detected against standard AFB1 sample purchased from Sigma Chemical Company (St. Louis, MO, USA). The maize oil suspended AFB1 (1/540 mL) was ready for biological use.

\section{$\mathrm{Cu}{ }^{+}$-Nicotinate Complex Preparation for Biological Use}

The $\mathrm{Cu}^{+}$-nicotinate complex was synthesized as previously described (Salama et al., 2007). In brief, $1.45 \mathrm{gm}$ of nicotinic acid was dissolved in $50 \mathrm{~mL}$ at 100 degrees Celsius distilled water. This mixture was added to an ethanol solution $\mathrm{CuCl}_{2}-2 \mathrm{H}_{2} \mathrm{O}(0.85 \mathrm{~g}, 40$ $\mathrm{mL})$. After mixture cooling, $0.5 \mathrm{gm}$ of $1(+)$-ascorbic acid was added and kept at room temperature till clear orange-red crystals were seen. In a boiling water bath, these crystals were purified in ethyl alcohol for $5 \mathrm{~min}$. The resultant pure and bright red needle crystals were inspected by an infrared spectrum, that indicated the chemical composition of $\left(\mathrm{Cu}^{+}\right.$-nicotinate $) 2 \mathrm{Cl}-2 \mathrm{H}_{2} \mathrm{O}$. 
$\mathrm{Cu}^{+}$-nicotinate complex molecular weight was $345 \mathrm{Da}$ and the cu content was $18.4 \%$. The daily requirement of $\mathrm{Cu}$, According to the National Research Council 2000 , is $73.6 \mu \mathrm{g} / \mathrm{kg}$ and $285.2 \mu \mathrm{g} / \mathrm{kg}$ for nicotinic acid. According to Shatat et al. (2013), the daily designed dose was $400 \mu \mathrm{g} / \mathrm{kg}$ body weight, within the allowance dose, where the crystal of complex was suspended in fresh maize oil to be given orally. The administered dose was within the allowance limit to avoid any toxicity.

\section{Design of the Experiment and Experimental Animals}

Animals were managed under the supervision of the Committee of the Ethics of Animal Experiments of South Valley University and under the guidance of the National Institutes of Health. Nineteen healthy male Wister albino rats weighted 120-150 grams were accommodated in appropriate normal conditions and divided into 3 groups: The reference group included five rats and was considered as a normal healthy standard ingested only by maize oil as a vehicle solution three times per week. The aflatoxicosed group consisted of seven rats orally treated with aflatoxin only $(30 \mu \mathrm{g} / \mathrm{kg}$ body weight), three times per week. The treated group consisted of seven rats treated by $\mathrm{Cu}^{+}$-nicotinate complex (400 $\mu \mathrm{g} / \mathrm{kg}$ body weight) concomitant with aflatoxin (30 $\mu \mathrm{g} / \mathrm{kg}$ body weight), three times per week.
At the end of the experiment (3 weeks), rats were sacrificed with an intraperitoneal injection of sodium pentobarbital $(100 \mathrm{mg} / \mathrm{kg})$ and hepatic tissue was extracted and prepared for gene expression analysis as well as histopathology screening (Fig. 1).

\section{tRNA Extraction}

mRNA was isolated using GENEzol reagent (\#15596018, Life Technologies, Palo Alto, CA) according to the manufacturer's guidelines. The mRNA concentration was detected using a Nanodrop ND-1000 spectrophotometer and the quality was evaluated by the 260/280 $\mathrm{nm}$ absorbance ratio.

\section{cDNA Synthesis}

cDNA was synthesized as follow: Solution of calculated amount of RNA of every sample completed to $10 \mu \mathrm{L}$ with nuclease-free water to obtain equal concentration of RNA in all samples where this volume was increased to $20 \mu \mathrm{L}$ after mixing with $10 \mu \mathrm{L}$ of $2 \mathrm{x}$ reverse transcription master mix, the mixture was incubated at $37^{\circ} \mathrm{C}$ for $120 \mathrm{~min}$ to prepare cDNA. $2 \mathrm{x}$ reverse transcription master mix was prepared by mixing $2 \mu \mathrm{L}$ 10x RT buffer, $0.8 \mu \mathrm{L} 25 \mathrm{x}$ DNTP Mix (100 Mm), 2 $\mu \mathrm{L}$ 10x RT Random primers, $1 \mu \mathrm{L}$ MultiScribe $^{\mathrm{TM}}$ Reverse Transcriptase, $1 \mu \mathrm{L}$ RNase inhibitor and $3.2 \mu \mathrm{L}$ Nuclease free water.

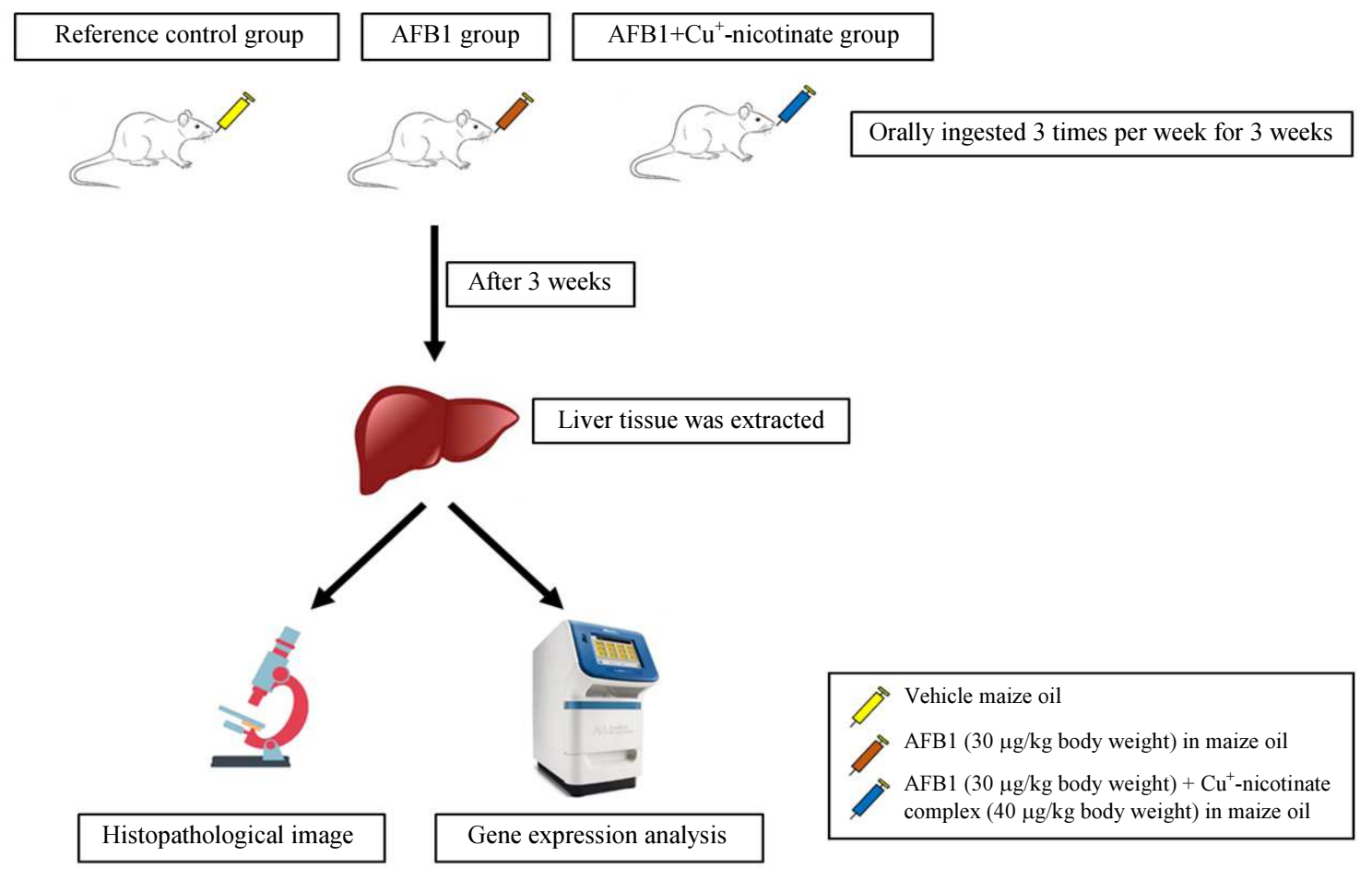

Fig. 1: A schematic diagram of the treatment schedule and study design 


\section{Quantitative Real-Time Polymerase Chain Reaction}

Real-time polymerase chain reaction (RT-PCR) using TaqMan gene expression assays (Applied Biosystems) and a Step One RT-PCR system (Applied Biosystems) were performed to determine rat mRNA levels. The primer and probe sets for each specific gene were as follows: Rn00561082 m1 (CYP1A2), Rn00756461_m1 (CYP3A2), Rn01502203_m1 (CYP2C11) and Rn01775763_g1 (GAPDH). The reaction underwent 40 cycles of the following: initial activation at $95^{\circ} \mathrm{C}$ for $10 \mathrm{~m}$, denaturation at $95^{\circ} \mathrm{C}$ for $15 \mathrm{~s}$ and annealing and extension at $60^{\circ} \mathrm{C}$ for $1 \mathrm{~m}$. Measurements of gene expression, as well as GAPDH, were performed. The expression of each gene was normalized to the expression of GAPDH and was calculated relative to control levels using the comparative threshold cycle method. To measure the gene expression of primers and GAPDH, PCRs were run in a total volume of $15 \mu \mathrm{L}$. The PCR mixture was prepared with $7.50 \mu \mathrm{L}$ Taqman Universal Master Mix II $(2 \mathrm{x}), 0.75 \mu \mathrm{L}$ Taqman genotyping assay mix (20x), 3.75 $\mu \mathrm{L}$ DNase-free water, $2.7 \mu \mathrm{L}$ cDNA and add 0.3 $\mu \mathrm{L}$ DNase free water to reach the final volume $15 \mu \mathrm{L}$.

\section{Histopathological Analysis}

The sections from liver tissue were promptly excised, which were fixed in $4 \%$ paraformaldehyde in phosphatebuffered saline. Paraffin sections with $5 \mathrm{~mm}$ thickness were prepared and stained with Hematoxylin and Eosin stain for histopathological observation.

\section{Statistical Analysis}

Data were expressed as mean \pm standard deviation and analyzed statistically using one-way ANOVA with Tukey Comparison Test as a post-test using GraphPad Prism version 6. P-values less than 0.05 were considered statistically significant. $* * \mathrm{P}<0.01$ and $* * * * \mathrm{P}<0.0001$.

\section{Results}

In our study, we isolated and purified AFB1 using silica gel colon chromatography where the toxin was suspended in maize oil checked on precoated plates of silica gel. The AFB1 specific chromatographic band was detected (left band) compared to the standard AFB1 sample (Right band, Fig. 2).

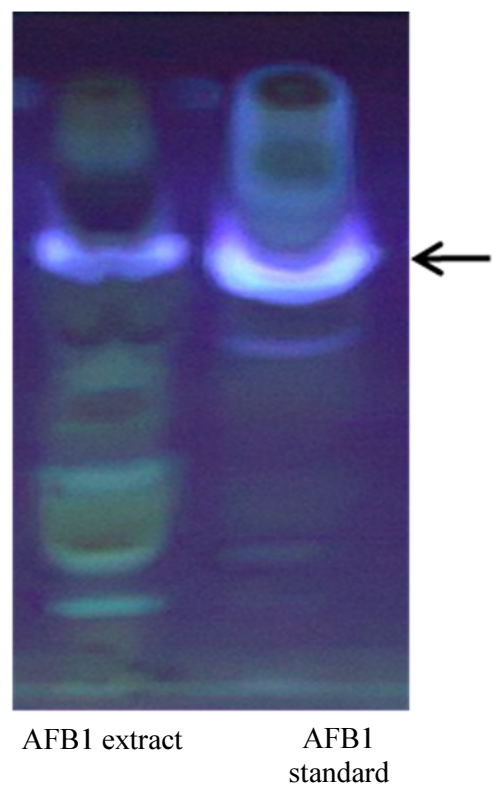

Fig. 2: Separation and identification of AFB1 by TLC (arrow) by methanol-chloroform (9:1) from mixture of biologically synthesized aflatoxins (left band) compared to standard AFB1 (right band) illuminated by UV

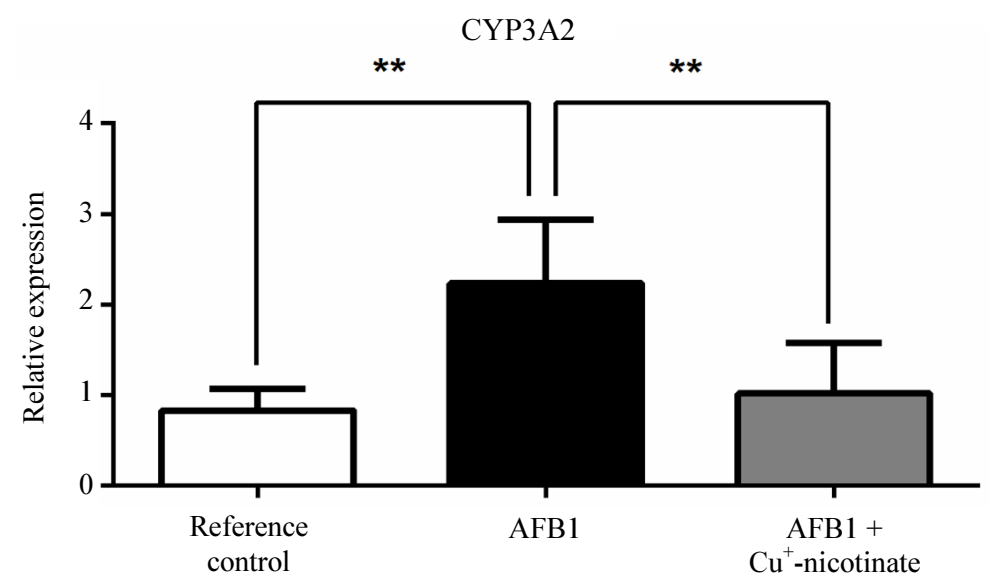

Fig. 3: RT-qPCR of CYP3A2 in reference control, $\mathrm{AFB} 1$ and $\mathrm{AFB} 1+\mathrm{Cu}^{+}$-nicotinate groups in rat hepatic tissue. Columns: relative frequency plus S.D. ${ }^{* * P}<0.01$ (one-way ANOVA followed by post-hoc Tukey's test) 
We further evaluated the expression level of CYP1A2, 3A2 and 2C11 in the hepatic tissue in different animal groups. We found that the gene expression of CYP450 families $3 \mathrm{~A} 2$ and $2 \mathrm{C} 11$ which convert AFB1 to the highly toxic metabolite was significantly increased in aflatoxicated rats $(p \leq 0.01)$ while rats which treated with $\mathrm{Cu}^{+}$-nicotinate concomitant with aflatoxin showed a significant reduction in the gene expression of these two families $(p \leq 0.01) \quad$ (Fig. 3 and 4$)$ showing no significant variance to the reference control group. In contrast, gene expression of CYP1A2 which convert AFB1 to the less toxic metabolite M1, P1 and Q1 was dramatically decreased in the aflatoxicated rats $(\mathrm{p} \leq 0.0001)$ compared to the $\mathrm{Cu}^{+}$-nicotinate treated group, while administration of $\mathrm{Cu}^{+}$-nicotinate concomitant with aflatoxin showed a sharply increase in the gene expression level of CYP1A2 with no obvious difference compared to the reference control group (Fig. 5).

Finally, we examined the histopathological changes in the hepatic specimen of different animal-treated groups. These observations were mostly confirmed such previous genes expression findings (Fig. 6). Untreated control animal group showed a healthy hepatic architecture (Fig. 6a) while aflatoxicosed liver specimen revealed degenerative changes in the hepatic parenchyma (Fig. 6b) as well as mononuclear inflammatory cells infiltration surrounding the portal tract (Fig. 6c). Treating aflatoxicosed animals with $\mathrm{Cu}^{+}-$ nicotinate showed an improvement of the hepatic architecture and all the histopathological signs of aflatoxicosis were almost absent (Fig. 6d).

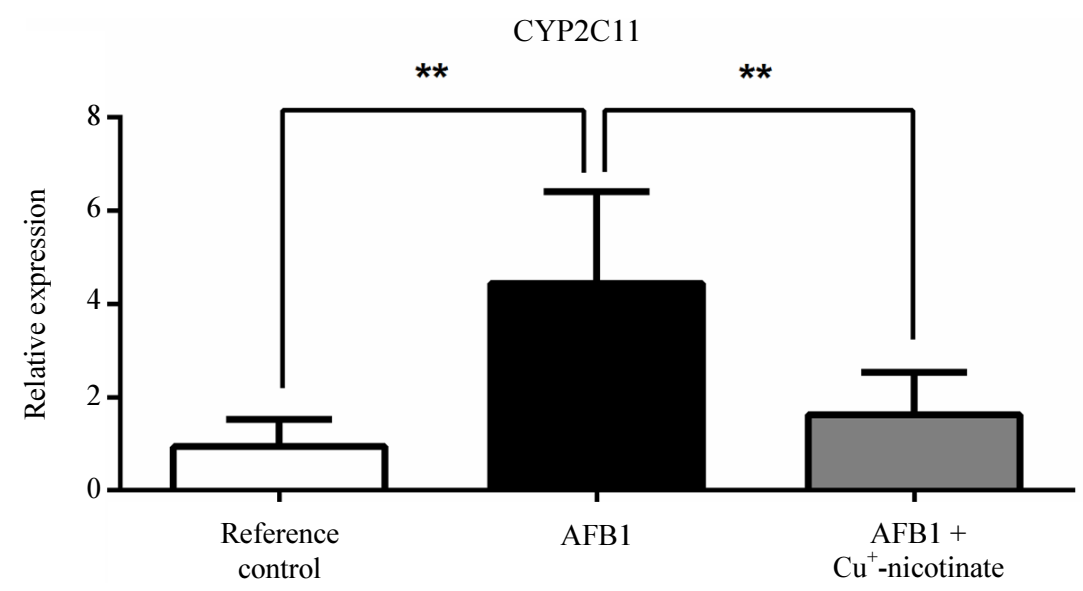

Fig. 4: RT-qPCR of CYP2C11 in reference control, $\mathrm{AFB} 1$ and $\mathrm{AFB} 1+\mathrm{Cu}^{+}$-nicotinate groups in rat hepatic tissue. Columns: relative frequency plus S.D. ${ }^{*} \mathrm{P}<0.01$ (one-way ANOVA followed by post-hoc Tukey's test)

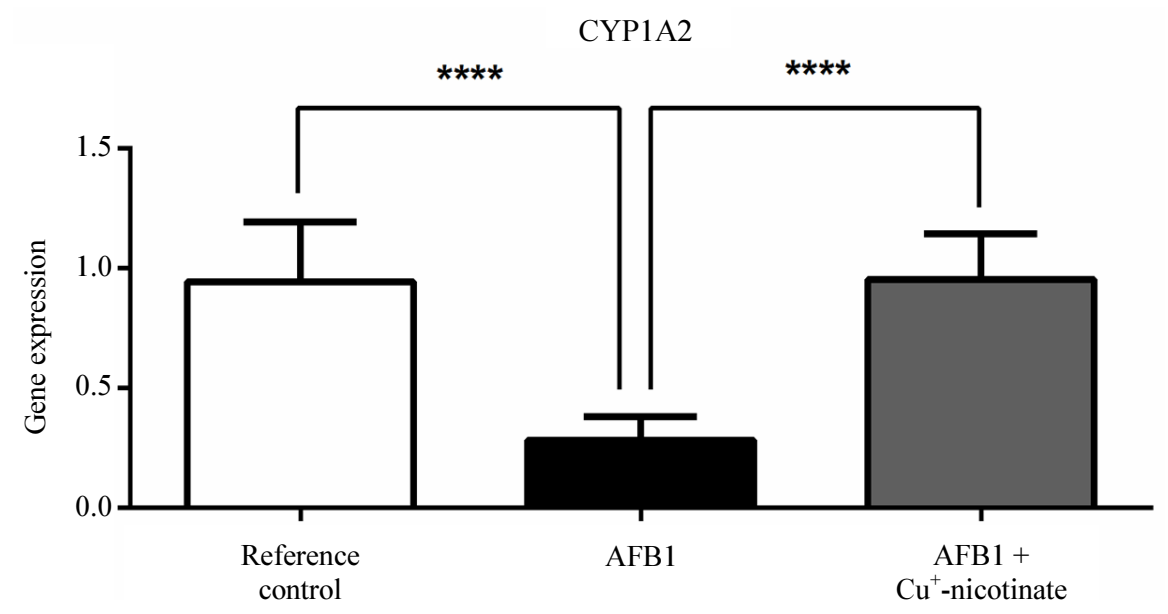

Fig. 5: RT-qPCR of CYP1A2 in reference control, $A F B 1$ and $A F B 1+\mathrm{Cu}^{+}$-nicotinate groups in rat hepatic tissue. Columns: relative frequency plus S.D. $* * * * \mathrm{P}<0.0001$ (one-way ANOVA followed by post-hoc Tukey's test) 


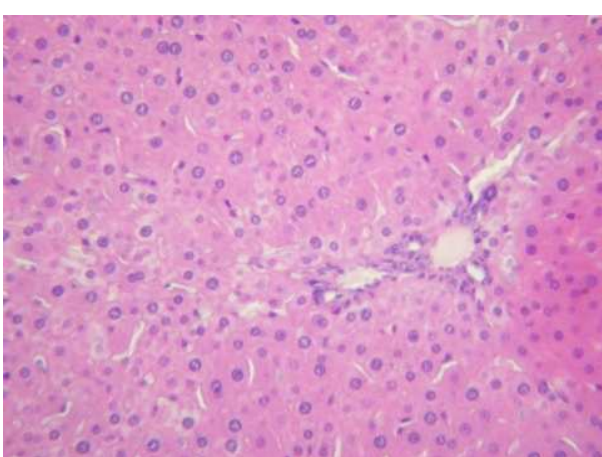

(a)

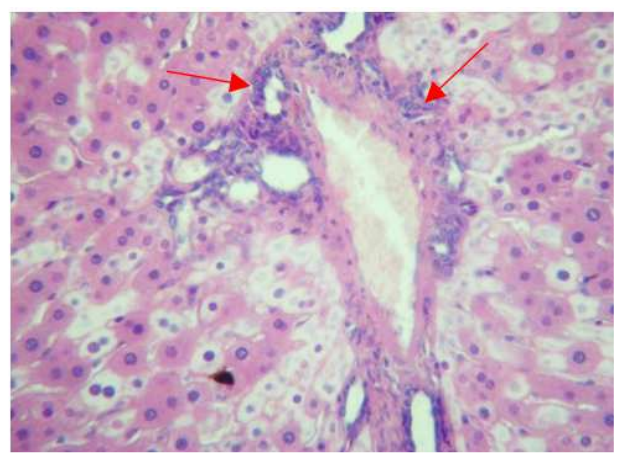

(c)

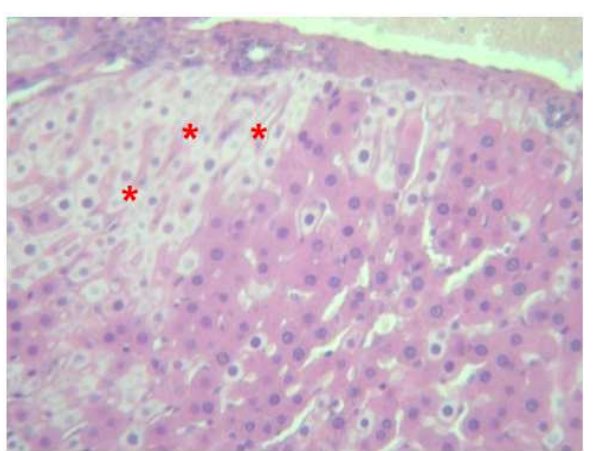

(b)

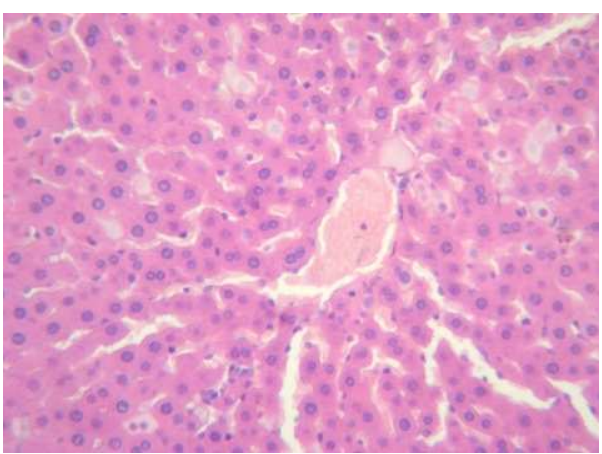

(d)

Fig. 6: Histopathological changes in the hepatic tissue. (a) Untreated animals revealed healthy and normal liver architecture. (b) Aflatoxicosed animals showed degenerative changes affecting liver parenchyma in the form of pale hepatic cell plates (star) radiating between cord of healthy looking ones as well as (c) portal tract was surrounded with mononuclear inflammatory cells infiltration (arrow). (d) $\mathrm{Cu}^{+}$-nicotinate-treated group exhibited improvement in hepatic architecture

\section{Discussion}

AFB1 is considered one of the most lethal menaces in food safety, owing to its hepatotoxic, carcinogenic, mutagenic and immunosuppressive effects on animals and humans (Kowalska et al., 2017). The metabolism of AFB1 varies in humans and animals where after ingestion of AFB1, it is metabolized mainly in the liver by different cytochrome p450 enzymes either to the highly genotoxic metabolites 8, 9 exo-epoxide or into the less toxic metabolites AFM1, AFP1 and AFQ1 (Wu et al., 2009). The present work has been designed to determine the role of $\mathrm{Cu}^{+}$-nicotinate complex on the gene expression of the hepatic CYP450 families in AFB1 induced rats. The complex that contains two daily required food elements; the $\mathrm{Cu}$ as well as nicotinic acid. They are considered active participants in oxidation-reduction cascades (Galhardi et al., 2005; Tupe et al., 2011). However, the presence of $\mathrm{Cu}$ in a free status is highly toxic to the host cells as it can likely transform between $\mathrm{Cu}^{+}$and $\mathrm{Cu}^{++}$ creating hydroxyl radicals that can impair essential biomolecules like proteins, lipids and nucleic acids (Lawson et al., 2016). In vivo, Cu transportation is often tightly attached to chaperone proteins that protect the body from the toxic effect of free metal ions (Nevitt et al.,
2012). $\mathrm{Cu}$ chelation, mimicking the protein chaperones, is the best path of shielding the metal ion to protect the body tissues from the biochemical damage presenting a therapy for $\mathrm{Cu}$ toxicity, $\mathrm{Cu}^{+}-$ nicotinate complex is a suitable chelating agent.

In a previous work, our group denoted that $\mathrm{Cu}^{+}-$ nicotinate complex directed the AFB1-metabolism towards synthesizing the less toxic metabolites P1, Q1 and M1 in these animals that were detected in their excreted urine (Nassar et al., 2014). However, the CYP450 enzymes that are incorporated in metabolizing AFB1 in the body is still a controversial issue. To confirm our previous findings, we analyzed the gene expression of most common CYP450 families including CYP1A2, CYP3A2 and CYP2C11 in the hepatic tissues. We found that the gene expression mechanism is not the same for all of these CYP450 families in normal healthy and normalized physiological conditions. Enzymes of less toxic Q1 and M1 were prominently increased than those of CYP2A3 or CYP2C11 in the tested hepatic tissue. It seems likely that in normalized conditions, the main responsible acting CYP450 against a normal low level of xenobiotic exposure are CYP1A1 and CYP1A2 producing the less toxic metabolites of AFB1. On acute AFB1-induction or moderate dose chronic intoxication $(30 \mu \mathrm{g} / \mathrm{kg}$ body 
weight for 3 weeks), the transforming enzyme to the carcinogenic epoxide metabolite (such as CYP2C11 and CYP3A2) was the more predominant families for such peroxidation. Treatment the $\mathrm{Cu}^{+}$-complex progressively inhibited such mechanisms by downregulation of CYP2C11 and CYP3A2 and sustained the normal levels of tested CYP1A2 producing Q1 and M1 (Fig. 7).

A previous study showed that treatment of aflatoxicosis using troleandomycin, a CYP3A inhibitor, resulting in $35 \%$ inhibition of AFB1-8,9-epoxide formation and Q1 metabolite formation was highly inhibited at all aflatoxin concentration levels (Ramsdell et al., 1991). Another study stated that aflatoxin Q1 metabolite is not extremely oxidized in human hepatic microsomes with low toxic effect compared to AFB1-8,9-epoxide formation and both of them can be controlled by CYP3A enzyme (Raney et al., 1992). More recent research tested the protective effect of coffee-specific diterpenes cafestol and kahweol complex against AFB1-inducing genotoxicity. Author found such treatment reduced the expression of both CYP2C11 and CYP3A2, the main enzymes that activate AFB1 to toxic AFB1-8,9-epoxide. They elaborated on the fact that this complex inhibited AFB1-DNA adduct formation (Cavin et al., 2001). Contrary to the previous findings, a group of researchers noted that AFB1 elevated both CYP1A activity and expression level that is accompanied by an increase in Ahr activity, suggesting that AFB1 can act as an Ahr agonist (Mary et al., 2015). Recent researches mentioned that the using of garlic and curcumin therapy against aflatoxicosis promoted AFB1 detoxification through suppression of hepatic CYPs including CYP1A1, CYP1A2, CYP2A6 and CYP3A4 (Zhang et al., 2016; El-Barbary, 2018). Accordingly, CYP450 is still playing a master role in the metabolism of various drugs and xenobiotics.

To approach the interpretation of the role of $\mathrm{Cu}^{+}-$ nicotinate for such haemostatic balance action, we have considered some of previous researches on copper and regulatory cell signaling pathways. Alexandra and White (2014) mentioned that copper showed a crucial role as a key regulator of cell signal transduction cascades of a complex sequence of interactions of key enzymes by modulation of $\mathrm{Cu}$-protein interactions. The extracellular copper is transported via ctr1, a copper transporter, in its monovalent ion than that divalent (Puig et al., 2002) which is facilitated by membrane metalloreductase. Subsequently, copper is delivered to the intracellular proteins and compartments by the action of copper chaperone for copper-zinc superoxide dismutase (Puig and Thiele, 2002; Culotta et al., 2006; Kim et al., 2008; Darwish et al., 2014). Accordingly, the used therapeutic copper complex in its monovalent makes it more visible for hepatic cellular membrane entrance.

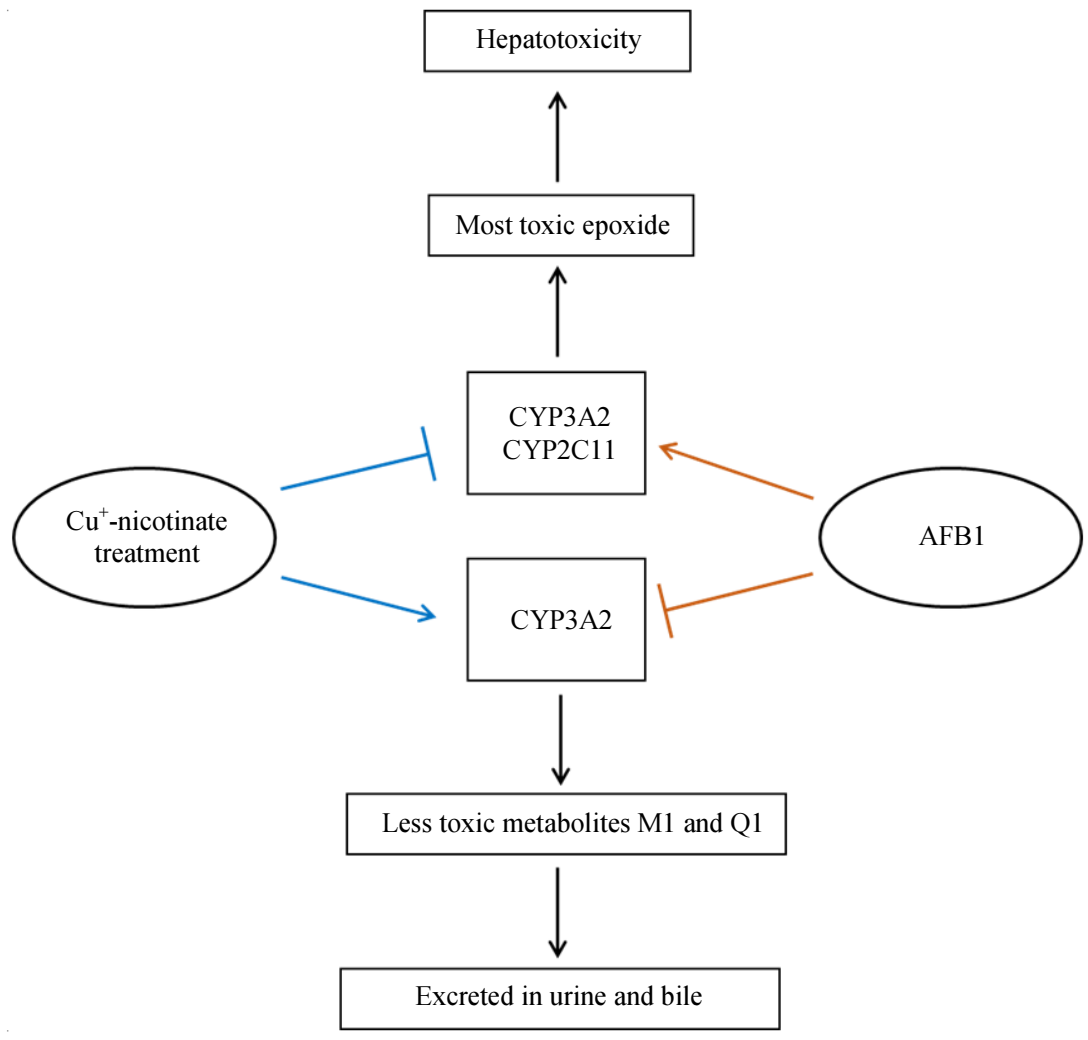

Fig. 7: A summary flow chart outlines the mechanism of $\mathrm{Cu}^{+}$-nicotinate in the treatment of aflatoxicosis in rats 
Recently Darwish et al. (2014) recognized that $\mathrm{Cu}^{++}$ $\left(\mathrm{CuSO}_{4}\right)$ slightly induced CYP1A1 and $1 \mathrm{~A} 2$ attributing such an increase for enhancement of ligand-protein cascade interactions (Whitlock, 1999). The authors stated that activation of AhR (aryl hydrocarbon receptor), which is a ligand-activated basic loop-helixloop transcriptional factor localized in the cytosol that might be attached to hsp 90 and an AhR Interacting Protein (AIP). Such a stimulating agent for AhR causes separation of hsp90 and AIP and thus the ligand-receptor complex translocates to the nucleus where it dimerizes with transcriptional factor protein aryl hydrocarbon receptor translocator. Therefore, that complex attaches to a certain DNA sequence called xenobiotic responsive element which is localized in the promoter site of the CYP1A1 gene (Morgan et al., 1994). Consequently, the inducing treating copper may initiate such a cascade protein complex interactions for sustaining the increase of CYP1A2 even the hepatic cell was exposed to aflatoxicosis. The significant observed reduction in the gene expression of CYP3A2, CYP2C11 induced by prophylactic $\mathrm{Cu}^{+}$-nicotinic acid could be attributed to specific suppression of CYP450 gene expression by cytokines in rat liver according to Saad et al. (2013). The author described that IL-1 in male rats produced a reduction in CYP3A2 and CYP2C11 mRNA as well as their protein expression. Hence, this $\mathrm{Cu}^{+}$-complex may act as immunopotentiator for such tested aflatoxicosed rats where its utilization was possibly associated with elevated levels of endogenous cytokines that promptly downregulate any enhancement in gene expression of CYP3A2 and CYP2C11 during such chronic AFB1 toxicosis.

\section{Conclusion}

$\mathrm{Cu}^{+}$-nicotinate complex presented as a proper biologically active $\mathrm{Cu}^{+}$for cell signaling to the aflatoxicosed liver tissue. The cellular response denoted that such predicted signaling preferably enhanced the CYP gene expression towards the 1A2 family more than the other types. Such a response significantly resulted in the accumulation of the less toxic metabolites M1 and Q1 instead of the other risky metabolites. Therefore, safety $\mathrm{Cu}^{+}$-nicotinate could be taken as a food additive for detoxification against aflatoxicosis exposure. The complex contains two daily required food elements; the copper within the Recommended Dietary Allowance (RDA) limits as well as nicotinic acid. Both of them are easily eliminated from the body via the digestive and urinary tracts when taken slightly overdose. Such controlling treatment could be achieved by further investigations. In brief, copper complexes are still an attracting field of research that could be applicable in biology and medicine.

\section{Funding}

This research did not receive any specific grant from funding agencies in the public, commercial, or not-forprofit sectors.

\section{Authors Contributions}

Mohammed Salah: Participated in the conception and design of the study, conducted the in vivo study, participated in the acquisition, analysis and interpretation of data, shared in drafting the article and revising it critically for important intellectual content and approved the final article.

Laila Mostafa and Ahmed R. Shatat: Conducted the in vivo study, shared in drafting the article and revising it critically and approved the final article.

Tahia H. Saleem: Participated in all acquisition, analysis and interpretation of data, shared in drafting the article and revising it critically and approved the final article.

Obeid Shanab and Muammar Y. Nassar: Analysis of data, shared in drafting the article and revising it critically for important intellectual content and approved the final article.

Enas A. Noseer: Acquisition of data, shared in drafring article and revising it critically for important intellectual content and approved the final article.

Ahmed Y. Nassar: Participated in the conception, shared in drafting the article and revising it critically and design of the study and approved the final article.

\section{Ethics}

This article is original and contains unpublished material. The corresponding author confirms that all of the other authors have read and approved the manuscript and no ethical issues involved.

\section{References}

Balina, A., A. Kebede and Y. Tamiru, 2018. Review on aflatoxin and its impacts on livestock. J. Dairy Vet. Sci., 6. DOI: 10.19080/JDVS.2018.06.555685

Belicchi Ferrari, M., F. Bisceglie, G. Gasparri Fava, G. Pelosi and P. Tarasconi et al., 2002. Synthesis, characterization and biological activity of two new polymeric copper(II) complexes with alphaketoglutaric acid thiosemicarbazone. J. Inorganic Biochem., 89: 36-44.

DOI: 10.1016/s0162-0134(01)00371-3

Booth, C., 1971. The Genus Fusarium. 1st Edn., Commonwealth Agricultural Bureaux [for the] Commonwealth Mycological Institute, England, pp: 237. 
Cavin, C., K. Mace, E.A. Offord and B. Schilter, 2001. Protective effects of coffee diterpenes against aflatoxin B1-induced genotoxicity: Mechanisms in rat and human cells. Food Chemical Toxicol., 39: 549-56. DOI: 10.1016/s0278-6915(00)00168-x

Culotta, V.C., M. Yang and T.V. O'Halloran, 2006. Activation of superoxide dismutases: Putting the metal to the pedal. Biochim. Biophys. Acta, 1763: 747-758. DOI: 10.1016/j.bbamcr.2006.05.003

Darwish, W.S., Y. Ikenaka, S. Nakayama and M. Ishizuka, 2014. The effect of copper on the mRNA expression profile of xenobiotic-metabolizing enzymes in cultured Rat H4-II-E cells. Biol. Trace Element Res., 158: 243-248.

DOI: $10.1007 / \mathrm{s} 12011-014-9915-9$

Diaz, G.J., H.W. Murcia, S.M. Cepeda and H.J. Boermans, 2010. The role of selected cytochrome P450 enzymes on the bioactivation of aflatoxin B1 by duck liver microsomes. Avian Pathol., 39: 279-285. DOI: $10.1080 / 03079457.2010 .495109$

El-Barbary, M.I., 2018. Impact of garlic and curcumin on the hepatic histology and cytochrome P450 gene expression of aflatoxicosis Oreochromis niloticus using RT-PCR. Turk. J. Fisheries Aquatic Sci., 18: 405-415. DOI: 10.4194/1303-2712-v18_3_06

El-Kady, I.A. and M.H. Moubasher, 1982. Toxigenicity and toxins of Stachybotrys isolates from wheat straw samples in Egypt. Exp. Mycol., 6: 25-30. DOI: $10.1016 / 0147-5975(82) 90060-3$

El-Saadani, M.A.M., 2004. A combination therapy with copper nicotinate complex reduces the adverse effects of 5-fluorouracil on patients with hepatocellular carcinoma. J. Exp. Therapeut. Oncol., 4: 19-24.

el-Saadani, M.A., A.Y. Nassar, S.H. Abou el-Ela, T.H. Metwally and A.M. Nafady, 1993. The protective effect of copper complexes against gastric mucosal ulcer in rats. Biochem. Pharmacol., 46: 1011-1018.

Galhardi, C.M., Y.S. Diniz, H.G. Rodrigues, L.A. Faine and R.C. Burneiko et al., 2005. Beneficial effects of dietary copper supplementation on serum lipids and antioxidant defenses in rats. Annals Nutrit. Metabolism, 49: 283-288. DOI: 10.1159/000087294

Grubman, A. and A.R. White, 2014. Copper as a key regulator of cell signalling pathways. Expert Rev. Molecular Med., 16: e11-e11.

DOI: $10.1017 /$ erm.2014.11

Halvorson, M.R., S.H. Safe, A. Parkinson and T.D. Phillips, 1988. Aflatoxin B1 hydroxylation by the pregnenolone-16 alpha-carbonitrile-inducible form of rat liver microsomal cytochrome P-450. Carcinogenesis, 9: 2103-2108.

Imaoka, S., S. Ikemoto, T. Shimada and Y. Funae, 1992. Mutagenic activation of aflatoxin B1 by pulmonary, renal and hepatic cytochrome P450s from rats. Mutat. Res., 269: 231-236.
Kew, M.C., 2013. Aflatoxins as a cause of hepatocellular carcinoma. J. Gastrointest. Liver Dis., 22: 305-310.

Kim, B.E., T. Nevitt and D.J. Thiele, 2008. Mechanisms for copper acquisition, distribution and regulation. Nature Chem. Biol., 4: 176-185. DOI: $10.1038 /$ nchembio.72

Kowalska, A., K. Walkiewicz, P. Kozieł and M. MucWierzgoń, 2017. Aflatoxins: Characteristics and impact on human health. Postepy Higieny Medycyny Doswiadczalnej, 71: 315-327.

DOI: $10.5604 / 01.3001 .0010 .3816$

Lawson, M.K., M. Valko, M.T.D. Cronin and K. Jomová, 2016. Chelators in iron and copper toxicity. Curr. Pharmacol. Rep., 2: 271-280. DOI: $10.1007 / \mathrm{s} 40495-016-0068-8$

Lin, Y.C., L. Li, A.V. Makarova, P.M. Burgers and M.P. Stone et al., 2014. Molecular basis of aflatoxininduced mutagenesis-role of the aflatoxin B1formamidopyrimidine adduct. Carcinogenesis, 35: 1461-1468. DOI: 10.1093/carcin/bgu003

Linder, M.C. and M.C. Linder, 1991. Introduction and overview of copper as an element essential for life. Biochem. Copper, 10: 1-13. DOI: $10.1007 / 978-1-4757-9432-8 \_1$

Lupo, G., N. Caporarello, M. Olivieri, M. Cristaldi and C. Motta et al., 2017. Anti-angiogenic therapy in cancer: Downsides and new pivots for precision medicine. Frontiers Pharmacol., 7: 519-519. DOI: $10.3389 /$ fphar.2016.00519

Luttfullah, G. and A. Hussain, 2011. Studies on contamination level of aflatoxins in some dried fruits and nuts of Pakistan. Food Control, 22: 426-429. DOI: 10.1016/j.foodcont.2010.09.015

Mandel, H.G., M.M. Manson, D.J. Judah, J.L. Simpson and J.A. Green et al., 1987. Metabolic basis for the protective effect of the antioxidant ethoxyquin on aflatoxin B1 hepatocarcinogenesis in the rat. Cancer Res., 47: 5218-5223.

Mary, V.S., A. Valdehita, J.M. Navas, H.R. Rubinstein and M.L. Fernández-Cruz, 2015. Effects of aflatoxin $\mathrm{B} 1$, fumonisin $\mathrm{B} 1$ and their mixture on the aryl hydrocarbon receptor and cytochrome P450 1A induction. Food Chem. Toxicol., 75: 104-111. DOI: $10.1016 /$ j.fct.2014.10.030

Monroe, D.H. and D.L. Eaton, 1987. Comparative effects of butylated hydroxyanisole on hepatic in vivo DNA binding and in vitro biotransformation of aflatoxin B1 in the rat and mouse. Toxicol. Applied Pharmacol., 90: 401-409.

Monroe, D.H., C.J. Holeski and D.L. Eaton, 1986. Effects of single-dose and repeated-dose pretreatment with 2(3)-tert-Butyl-4-Hydroxyanisole (BHA) on the hepatobiliary disposition and covalent binding to DNA of aflatoxin B1 in the rat. Food Chem. Toxicol., 24: 1273-1281. 
Morgan, E.T., K.B. Thomas, R. Swanson, T. Vales and J. Hwang et al., 1994. Selective suppression of cytochrome P-450 gene expression by interleukins 1 and 6 in rat liver. Biochim. Biophys. Acta, 1219: 475-483. DOI: 10.1016/0167-4781(94)90074-4

Mulenga, D. and S. Siziya, 2019. Indoor air pollution related respiratory ill health, a sequel of biomass use. SciMedicine J., 1: 1-8.

DOI: $10.28991 /$ SciMedJ-2019-0101-5

Musa, S.A., A.H. Hafez, A.Y. Nassar and M.A. Gohar, 1987. Copper(I)-Nicotinic Acid Complex: An Immunopotentiator in Chickens Vaccinated Against Newcastle Disease. In: Biology of Copper Complexes, Sorenson, J.R.J. (Ed.), Humana Press, Totowa, NJ, pp: 343-350.

DOI: 10.1007/978-1-4612-4584-1_26

Nassar, A.Y., A.M. Ali, M.A. El-baz, H.M.S. Eldien and S. Yousif et al., 2014. Copper (I)-nicotinate complex promoted the synthesis of aflatoxin M1 and Q1 more efficiently than butylated hydroxytoluene in aflatoxicosed rats. Global Adv. Res. J. Medicine Medical Sci., 3: 298-307.

Nassar, M.A.Y., H.M.S. Eldien, H.S.A. Tawab, T.H. Saleem and H.M. Omar et al., 2012. Timedependent morphological and biochemical changes following cutaneous thermal burn injury and their modulation by copper nicotinate complex: An animal model. Ultrastructural Pathol., 36: 343-355. DOI: $10.3109 / 01913123.2012 .685687$

Nevitt, T., H. Öhrvik and D.J. Thiele, 2012. Charting the travels of copper in eukaryotes from yeast to mammals. Biochim. Biophys. Acta - Molecular Cell Res., 1823: 1580-1593.

DOI: 10.1016/j.bbamcr.2012.02.011

Penning, T.M., 2011. Chemical Carcinogenesis. 1st Edn., Springer, New York, ISBN-10: 1617379956 , pp: 440

Puig, S., J. Lee, M. Lau and D.J. Thiele, 2002. Biochemical and genetic analyses of yeast and human high affinity copper transporters suggest a conserved mechanism for copper uptake. J. Biol. Chem., 277: 26021-26030. DOI: 10.1074/jbc.M202547200

Puig, S. and D.J. Thiele, 2002. Molecular mechanisms of copper uptake and distribution. Curr. Opin. Chem. Biol., 6: 171-180.

Ramsdell, H.S., A. Parkinson, A.C. Eddy and D.L. Eaton, 1991. Bioactivation of aflatoxin B1 by human liver microsomes: Role of cytochrome P450 IIIA enzymes. Toxicol. Applied Pharmacol., 108: 436-447.

Raney, K.D., T. Shimada, D.H. Kim, J.D. Groopman and T.M. Harris et al., 1992. Oxidation of aflatoxins and sterigmatocystin by human liver microsomes: Significance of aflatoxin Q1 as a detoxication product of aflatoxin B1. Chem. Res. Toxicol, 5: 202-210. DOI: 10.1021/tx00026a009.
Rotimi, O.A., S.O. Rotimi, J.M. Goodrich, I.B. Adelani and E. Agbonihale et al., 2019. Time-course effects of acute aflatoxin B1 exposure on hepatic mitochondrial lipids and oxidative stress in rats. Frontiers Pharmacol., 10: 467-467. DOI: $10.3389 /$ fphar.2019.00467

Saad, T.T., Z.K. El-Meadawy, M.A. Ali and A.I.E. Fayza, 2013. Some studies on the effect of copper (I) nicotinate complex on the immune response and some biochemical parameters of sea bass fish vaccinated with Yersinia Ruckeri Bacterin. World's Vet. J., 3: 74-81.

Salama, R.H.M., A.Y.A. Nassar, A.A.M. Nafady and H.H.T. Mohamed, 2007. A novel therapeutic drug (copper nicotinic acid complex) for non-alcoholic fatty liver. Liver Int., 27: 454-464. DOI: $10.1111 /$ j.1478-3231.2007.01460.x

Sarma, U.P., P.J. Bhetaria, P. Devi and A. Varma, 2017. Aflatoxins: Implications on health. Indian J. Clin. Biochem., 32: 124-133. DOI: $10.1007 / \mathrm{s} 12291-017-0649-2$

Shatat, A.R., H.M. Saad Eldien, M.Y. Nassar, A.O. Mohamed and A. Haleem et al., 2013. Protective effects of copper (I)-nicotinate complex against aflatoxicosis. Open Toxicol. J., 6: 1-10.

Shimada, T., S. Nakamura, S. Imaoka and Y. Funae, 1987. Genotoxic and mutagenic activation of aflatoxin B1 by constitutive forms of cytochrome P450 in rat liver microsomes. Toxicol. Applied Pharmacol., 91: 13-21.

Sorenson, J.R.J., 1987. Biology of Copper Complexes. 1st Edn., Humana Press, Totowa, NJ, ISBN-10: 0896031233, pp: 598.

Suksrichavalit, T., S. Prachayasittikul, T. Piacham, C. Isarankura-Na-Ayudhya and C. Nantasenamat et al., 2008. Copper complexes of nicotinic-aromatic carboxylic acids as superoxide dismutase mimetics. Molecules, 13: 3040-3056.

DOI: 10.3390/molecules 13123040

Tupe, R.S., S.G. Tupe and V.V. Agte, 2011. Dietary nicotinic acid supplementation improves hepatic zinc uptake and offers hepatoprotection against oxidative damage. British J. Nutrit., 105: 1741-1749. DOI: $10.1017 / \mathrm{S} 0007114510005520$

Vančo, J., J. Marek, Z. Trávníček, E. Račanská and J. Muselík et al., 2008. Synthesis, structural characterization, antiradical and antidiabetic activities of copper(II) and zinc(II) Schiff base complexes derived from salicylaldehyde and $\beta$ alanine. J. Inorganic Biochem., 102: 595-605. DOI: 10.1016/j.jinorgbio.2007.10.003

Wang, J.S. and J.D. Groopman, 1999. DNA damage by mycotoxins. Mutation Research/Fundamental Molecular Mechanisms Mutagenesis, 424: 167-181. DOI: 10.1016/S0027-5107(99)00017-2 
Whitlock, J.P., 1999. Induction of cytochrome P4501A1. Annual Rev. Pharmacol. Toxicol., 39: 103-125. DOI: 10.1146/annurev.pharmtox.39.1.103

Wu, Q., A. Jezkova, Z. Yuan, L. Pavlikova and V. Dohnal et al., 2009. Biological degradation of aflatoxins. Drug Metabolism Rev., 41: 1-7.

DOI: $10.1080 / 03602530802563850$
Zhang, N.Y., M. Qi, L. Zhao, M.K. Zhu and J. Guo et al., 2016. Curcumin prevents aflatoxin B1 hepatoxicity by inhibition of cytochrome P450 isozymes in chick liver. Toxins, 8: E327-E327. DOI: $10.3390 /$ toxins 8110327 